
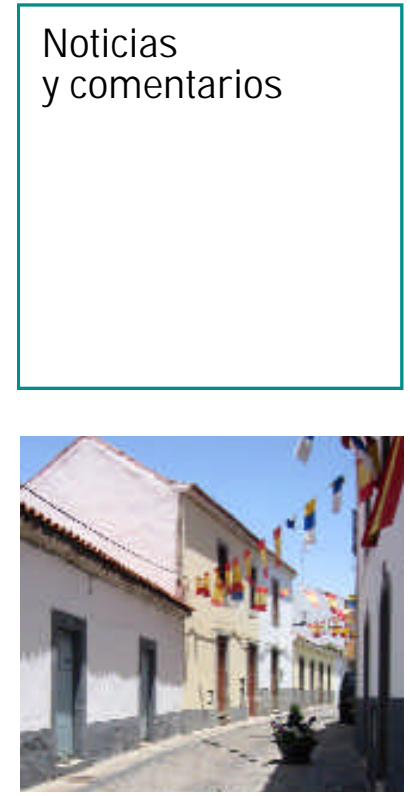

Arquitectura del núcleo urbano de Vega de San Mateo (Gran Canaria)

\title{
Aportaciones de las II J ornadas de Gestión del Patrimonio Histórico
}

Bajo este título se desarrollaron, desde el pasado 15 al 18 de noviembre de 2005, las II J ornadas de Gestión del Patrimonio Histórico (GEPA) en el municipio de Vega de San Mateo (Gran Canaria).

El objetivo de estas II GEPA ha sido convertirse en un punto de reflexión de conceptos como museografía, museología, exposición, pedagogía del patrimonio, así como del papel de los museos en el complejo mundo de la educación. Con tal fin se presentó una muestra de la gestión educativa y cultural llevada a cabo en los museos, y se analizaron aquellos elementos que dan lugar a lo que conocemos como Patrimonio histórico - cultural y que, como si de una buena comida se tratara, han de combinarse para dar como resultado su adecuada difusión y conocimiento óptimo.

Las jornadas se estructuraron en torno a tres grandes temas: difusión del Patrimonio, recursos pedagógicos y nuevas propuestas educativas en los museos.

\section{Difusión del Patrimonio}

Abrió la jornada Ana Fernández Garrido, quien planteó una aproximación histórica y actual al vocablo museo y a los elementos que lo componen.

Posteriormente intervino María Luisa Bellido Gant, de la Universidad de Granada, quien cuestionó la situación actual de los museos, tratados como grandes catedrales del ocio y vinculados cada vez más a la obra arquitectónica que los contiene, en vez de a la propuesta educativa y a la labor de difusión que realizan.

Al concluir esta segunda conferencia tuvo lugar un turno de comunicaciones, en el que expusieron Jennifer Godoy Pérez, que habló del proyecto educativo de la Casa de Colón (Gran Canaria), y Guacimara Batista Rivero, que analizó el estado actual de la gestión de los archivos mediante el ejemplo del archivo municipal de Vega de San Mateo.

\section{La pedagogía en el museo}

En este segundo bloque se contó con la intervención de dos especialistas en materia pedagógica. Por una parte Natalia Ferrando Rodríguez, del Centro de Arte La Regenta (Gobierno de Canarias), nos acercó a las exposiciones como recurso didáctico a través de una visita guiada. Por otra, Inmaculada Pérez Maza, del Centro Atlántico de Arte Moderno (CAAM) realizó un análisis de la importancia de los Departamentos de Educación y Acción Cultural (DEAC) en los Centros de Arte, y de los actuales mecanismos pedagógicos para atraer la atención y el interés del espectador.
El tercer día de las II GEPA se centró en un taller práctico de musealización, impartido por Nerio Martín Sánchez Mestre, del Museo de Arte Nacional de Maracaibo (Venezuela). El taller consistió en una breve introducción en la que se expusieron algunas estrategias de cómo musealizar un espacio, así como algunas nociones básicas del concepto y la práctica de la interpretación. Posteriormente, los asistentes visitaron el núcleo histórico de Vega de San Mateo, guiados por gonzalo Armas Merino y Pedro J. Rodríguez Suárez. Para concluir, y divididos en grupos de tres, realizaron un análisis DAFO (debilidades, amenazas, fortalezas, y oportunidades) de este núcleo urbano y una propuesta de musealización del mismo.

\section{Museos y Educación}

El último bloque de las jornadas se ocupó de las nuevas propuestas para el museo y la educación. Intervino Rafael C. Gómez León, de la Asociación Cultural Pinolere (Tenerife), con la exposición del proyecto comunitario que tiene como eje el Museo Etnográfico de las Casas Pajizas de Pinolere, que se desarrolla desde hace varios años en La Orotava.

A esta conferencia le siguió una nueva intervención de Nerio Martín Sánchez Mestre en la que abordó el tema de los museos virtuales, en concreto del Museo Virtual de Zulia (Venezuela).

Como colofón y clausura de las II GEPA, se inauguró una exposición de fotografías históricas cedidas por la Fundación para la Etnografía y el Desarrollo de la Artesanía Canaria (FEDAC), dependiente del Cabildo de Gran Canaria. Además se hizo entrega, por parte de Miguel Hidalgo Sánchez, alcalde de Vega de San Mateo, del I Premio a la Conservación del Patrimonio. En breve se espera disponer del libro de actas de las II GEPA .

La experiencia positiva de las I y II GEPA nos anima a continuar con este proyecto que surgió con la ilusión de incorporar un análisis de la gestión patrimonial en el Archipiélago Canario.

Más información:

Web: www.vegasanmateo.es

Correo-e: culturaypatrimonio@vegasanmateo.es

Ma Carmen Naranjo Santana

Concejal de Cultura y Patrimonio

Ayuntamiento de Vega de San Mateo 